\title{
The Introduction of Compulsory Schooling Around the World: Global Diffusion Between Isomorphism and 'Cultural Spheres'
}

\section{Helen Seitzer, Fabian Besche-Truthe, and Michael Windzio}

\section{Introduction ${ }^{1}$}

State-regulated education has a long history, with its earliest mentions appearing in the Talmud, in Ancient Greece and later during the Enlightenment (Weymann 2014). Virtually every society has established some form of education over time (Craig 1981, 191f). Most early forms of education, however, were limited to particular groups, for example,

\footnotetext{
${ }^{1}$ This chapter is a product of the research conducted in the Collaborative Research Center "Global Dynamics of Social Policy" at the University of Bremen. The center is funded by the Deutsche Forschungsgemeinschaft (DFG, German Research Foundation)—project number 374666841SFB 1342 .
}

H. Seitzer $(\bowtie) \bullet$ F. Besche-Truthe

Collaborative Research Centre 1342 "Global Dynamics of Social Policy", University of Bremen, Bremen, Germany e-mail: seitzer@uni-bremen.de; fbesche@uni-bremen.de 
boys from the ruling class, military commanders, or people of the clergy. Most of the beneficiaries were traditionally chosen to maintain the social and political equilibrium and keep certain people in power (Boli et al. 1985)_education was a means to shape the future elite (Weymann 2014). Moreover, education was and still is strongly tied to local culture, for example, the Protestant Reformation (Ramirez and Boli 1987). Historically, religious traditions and class conflict have strongly shaped the development of state-regulated education.

In this chapter, we apply a relational concept of 'culture', in which shared cultural traits are assumed to shape the diffusion process of social policies, as it allows for easier communication between these countries. We elaborate how this concept of culture relates to education as a means of socialization, but also how different 'cultural spheres' can influenceaccelerate or decelerate- the diffusion of global norms such as the introduction of standardized schooling. To this extent, we explore empirically how compulsory education developed around the globe, and we test the influence of membership in certain 'cultural spheres' on the introduction of compulsory education. Researching policy diffusion requires a combination of processes on the local as well as the global level, which we account for by combining network analysis with event history analysis for diffusion (Valente 1995).

The origin of state-regulated compulsory schooling for all children can be traced back to Europe. We argue that culture cannot be ignored as a driving force behind the diffusion of social policies and suggest a relational approach. Cultural similarity establishes a linkage between groups, which increases communication and exchange. We measure culture in a way that allows countries not only to share cultural characteristics in varying strengths but also to change their culture over time. Cultures and their differences result from shared histories, traditions, exchange, and power relations, all of which develop over time and bind some countries

\section{Windzio}

SOCIUM and Collaborative Research Centre 1342 "Global Dynamics of Social Policy”, University of Bremen, Bremen, Germany e-mail: mwindzio@uni-bremen.de 
closer together, but also allow them to drift apart over time. Cultures are not fixed or mutually exclusive entities. Nevertheless, compulsory education corresponds with the reproduction and change of a country's culture and drives the process of modernization. As we know from international comparative research, there are different pathways into modernity, so the role of education in the reproduction and change of a nation state's culture might differ as well (Weymann 2014).

Yet, global cultural differences are still a neglected issue in studies on the development of education systems. If educational standards differ from local cultures and traditions, powerful actors in some countries could even oppose the introduction of (standardized) compulsory education. Accordingly, we expect the diffusion of compulsory education around the globe to depend on local cultural factors.

In this chapter, we identify a limited set of cultures in the world as 'cultural spheres' (see Chap. 1) and analyze their importance for the diffusion of education policy. We analyze the diffusion of compulsory education by focusing on countries' membership in fuzzy clusters defined by cultural characteristics. By deriving clusters from a valued two-mode social network analysis, we explicitly consider the overlapping boundaries and fuzzy set character of cultural spheres in contrast to rigid 'fault lines' (Huntington 1993). We measure cultural spheres by indicators such as religion and language, and test their impact on the diffusion of compulsory education, controlling for indicators of economic development, democratization, and colonial legacies.

In the following sections, we first discuss the role of culture in the diffusion process of institutionalized education. Subsequently, we illustrate the reproduction of culture and social order through standardized education and the effects of its increasing isomorphism. Lastly, after introducing our estimation method, we extensively illustrate the cultural spheres we have identified and their impact on the adoption of compulsory education policy. 


\section{Culture and the Diffusion of Education Systems}

The definition of 'culture', its influence on individual behavior, and its global differences have become a central controversy within the social sciences (Anderson-Levitt 2012). Marxists regard culture as a superstructure determined by productive forces and the organization of property rights. As an outcome of a progressively simplified class structure in capitalist societies, class-consciousness is a condition of class conflict-an essential concept in Marxist theory (Lockwood 1992). Although Max Weber considered the importance of economic organization for the development of societies, he focused on the impact of religious orientation and the evolution of Occidental rationalism, economic motives, and specific forms of authority. Long-term historical path dependencies led to remarkable differences between global cultures (Weber 1972), and these differences are still important today. Nevertheless, cultures are not stable entities but embedded in a network of socially constructed elements. There is no objective point of reference when we contrast different cultures. For example, when we evaluate the degree of individualism in a society, we can just compare average levels of individualism between societies. As we know from social network analysis, elements of culture relate to each other like fuzzy set clusters and mutually give each other meaning (Emirbayer and Goodwin 1994; Emirbayer 1997, 299). In our view, a more relational approach to the concept of culture allows for the analysis of culture as a determinant of policy diffusion through networks without the identification of 'fault lines'.

\section{Culture and the Legitimacy of Order}

Various academic perspectives define culture by using a set of common principles: beliefs, norms, symbols, values, and meanings, which are part of a shared stock of knowledge in a given community (Rose 2019; Basáñez 2016). Such a community can be local or global, the latter being especially prevalent in times where transnational online activities are highly influential (Anderson-Levitt 2012). Elements of culture must be transmitted from one person to another, for example, by communication, by 
intergenerational transmission within families, and by educational institutions. The sustainability of cultural elements depends on their spatial distribution and stability over time, so that transmission is possible. Yet most ideas and practices created by individuals will never pass the transmission threshold and will not enter stable diffusion chains; therefore, they do not become part of a socially shared stock of knowledge. The more attractive ideas and practices are, the higher their likelihood of becoming part of a social tradition. Attractiveness and accessibility of cultural elements fuel their diffusion by repetition, redundancy, and proliferation (Morin 2016, 146). Furthermore, the attractiveness of a cultural element is determined, among other things, by its adaptability and benefit to the community (Meyer et al. 1997).

Culture exists not only as shared knowledge in the minds of individuals but also in an 'objectified state'. An individual should not expect to influence the objectified culture in a substantive way (Parsons and Shils 1951, 58-66). Nevertheless, in liberal-pluralistic and culturally diverse societies, interpretations of norms and symbols are flexible, debatable, and subject to negotiation. People can be part of multiple subcultures, or they are accepted by only some members of a culture but not others (Anderson-Levitt 2012). Ironically, although there is no 'essence' of a culture, culture is nevertheless of crucial importance for a society's social and economic order (Emirbayer and Goodwin 1994; Rose 2019). Societies need minimum consensus on values, normative expectations, and the meaning of symbols (Parsons and Shils 1951; Rose 2019).

In their study on economic development and political stability, Acemoglu and Robinson (2019) emphasize the role of institutions, but we know from Weber (1972) that different forms of authority and institutionalized order show varying levels of stability. This variance in stability strongly depends on the legitimacy of order, particularly from the administration's point of view but also from that of the general population. The German constitutional lawyer Böckenförde (1976) emphasized that the "liberal and secular state is based on conditions which this state itself is unable to guarantee ... and this is the risk the liberal state has taken for the sake of freedom" (Böckenförde 1976, 60). ${ }^{2}$ It is another way

\footnotetext{
${ }^{2}$ Own translation.
} 
of expressing the importance of Weber's concept of legitimized order. Legitimacy of institutions and social order results from shared taken-forgranted knowledge, which is a crucial aspect of a country's culture. The liberal state needs a cultural foundation. Being liberal, it cannot enforce this culture by law but depends on the appropriate socialization of its citizens. Moreover, it gains legitimacy by actions regarded as efficient and beneficial. The liberal nation-state, which was formed in the eighteenth and nineteenth centuries, operates in a (world) society of 'sovereign' nation-states in which legitimacy of state action is mutually dependent on and influenced by the actions of other members of that society (Meyer et al. 1997).

Culturally defined goals of statehood became universal, crossing borders around the globe. For legitimization, states need to fulfill specific functions, for example, ensuring national, individual, economic, and social progress (Ramirez and Boli 1987), or the inclusion of societal groups in the state's social and political framework (Wallerstein 2007).

This framework of nation-state formation (Green 2013) crucially relies on the individual as the focus of attention and the cornerstone of economic and societal action. This individualistic shift away from communal units like family, clan, or small religious and ethnic groups is inherently European and was largely brought forward by the prohibition of intrafamily marriage (Henrich 2020). These norms became even more common as a result of the Reformation, which devalued the church collective and emphasized individual action as the appropriate pathway to salvation (Ramirez and Boli 1987, 12). Modern norms and values are in line with the state's effort to control progress through individual education. In other regions of the world, this cultural turn came after the nineteenth century, if at all. Nevertheless, we can deduce that (state) legitimacy as an element of culture conceptually links social and political order, on the one hand, and education systems, on the other hand. Education systems are systematic means to transfer the standards of state legitimacy to future generations. Institutionally similar configurations, especially the concept of 'sovereign nation-states', with their similar purposes of economic growth, human rights, and social equality, have proven to be accelerators for the diffusion of abstract norms and values (Strang and Meyer 1993). 


\section{Institutionalized Education and the Transmission of Culture}

Only through the acceptance of concepts such as 'nation', 'citizenship', and 'culture' can the state legitimize the implementation of rules and norms regulating the lives of its citizens through laws and education (Schriewer 2012). Just as citizens regard themselves as part of a local and national culture, nation-states are characterized by culture to some degree (Basáñez 2016, 16). 'Vertical' transmission of knowledge by teaching a predefined curriculum to children and adolescents in schools became a functional requirement of modern societies, which are based upon highly specialized knowledge in various fields. A major part of cultural transmission in modern societies falls on educational institutions. While anthropologists focus on the 'bottom-up' evolution of culture, or more precisely on gene-culture coevolution (Henrich 2016), sociological neoinstitutionalism (Meyer et al. 1997) advances Weber's view on the consolidation of rational institutions during the transition into modernity. Modern institutions are so efficient that Weber (1972) suspected the emergence of 'iron cages', in which individuals are trapped and execute instructions in dehumanized bureaucracies. Neo-institutionalists (Meyer et al. 1997) argue that Western organizational forms transcend the boundaries of Western culture due to their general efficiency in organizing state and society. The evolution of the Occidental culture took a rather specific path in Weber's view, whereby Western rationalization and secularization resulted in remarkable differences to other cultures. Western individualism is regarded as Western, educated, industrialized, resourceful, and democratic (WEIRD) (Schulz et al. 2019; Henrich 2020). WEIRD cultures lean toward individualism and independence, toward impersonal pro-sociality (e.g. trust to strangers), and less toward obedience and conformity. Anthropologists agree with Weber on the importance of religion, but according to Schulz et al. (2019) and Henrich (2020), Westerners became WEIRD due to the marriage policies of the Western Church. The Church prohibited marriage between cousins and repressed the influence of extended families and clans, which resulted in 
higher individualism and an increased reliance on state institutions for competition and conflict resolution (Henrich 2020, 323-359).

As a result, modernity strongly depends on institutions; nowadays, it also depends on international and supranational organizations such as the European Union (EU), the World Trade Organization (WTO), the International Labour Organization (ILO), and others. These organizations tend to be bureaucratic, so that they can survive and efficiently attain their goals. Their organizational culture tends to be WEIRD as well. Becoming an accepted part of these organizations serves as a legitimization tool for some countries. The implementation of compulsory education, for example, is a common tool of legitimization for states (Meyer et al. 1997). How important these institutions are in guiding peoples' behavior, however, is a different question. The acceptance of a global culture can be more of a performative act than an integration of these norms into the local belief system (Steiner-Khamsi 2000); it can be just "myth and ceremony" (Meyer and Rowan 1977). Nevertheless, IO membership demonstrates a country's affiliation with the group of countries already following these norms and increases a country's 'social standing' within the group. In our globalized world, individuals and organizations are interested in shared institutionalized standards when they interact across different national institutions. Modern, Western bureaucracies tend to spread around the world due to their efficiency (Meyer et al. 1997) but also because international organizations require predictable, reliable, and accountable organizational standards. The impressive isomorphism portrayed by nation-states as well as IOs becomes evident, for instance, when states establish a bureaucracy charged with managing science policy even though the need for it is hardly justifiable (Finnemore 1993). According to neo-institutionalists, actors, individuals, and organizations evolve in an environment with predefined expectations and aspirations along with standardized modes of reaching these goals. Since World War II, this environment has gained strength in penetrating nation-states' development, rendering domestic structural, cultural, and historical factors less impactful (Benavot and Riddle 1988, 204). Isomorphism proceeds covertly 'behind our backs'. However, we suspect that culture and identity, for example, in terms of Protestantism and Catholicism, were fundamental influences on the formalization of 
institutions, especially during the early time frame of our study (Boli et al. 1985,165$)$.

Even today, culture and identity are still important issues in the domestic politics of many Western countries, but they are also critical at the global level (Fukuyama 2018), having become highly controversial since the mid-1990s. For example, Huntington (1993) argued that religiouscultural 'fault lines' now separate different civilizations from each other, and it is at these fault lines that future global conflicts would occur (Huntington 1996). Although many global conflicts result from diverging economic interests and many future conflicts might result from environmental deterioration, Huntington made us aware of the role played by ethnic, cultural, and religious movements. These facets were hidden during the Cold War but became visible since the early 1990s. Huntington pointed to culture as a crucial issue due to potential tensions between different cultures and civilizations.

His typology of civilizations (Huntington 1996) is rather rough, and stimulated severe criticism for good reason (Norris and Inglehart 2011, 134-137). As demonstrated above, culture exists at different levels (Basáñez 2016, 16), for example, in romantic relationships, small groups, but also in nation-states, or supra-national entities such as the EU. We must either allow some abstraction when we analyze cultures at higher levels (Anderson-Levitt 2012, 443), or we must give up the concept entirely and thereby implicitly regard cultural diversity at the global level as intractable to scientific inquiry. In accordance with Chap. 1, we expect culture to be a shaping force, influencing the spread of state education systems, because it is inherently interwoven with education, which is affected by cultural configurations and charged with transmitting them. We argue that culture, as a domestic factor, accelerated or delayed global isomorphic tendencies.

\section{Institutionalized Education and Society}

The first observation of a spread of Western values impacting schooling and, in turn, society is through the introduction of modern mathematics. There have been various ways of calculating throughout human history, 
but the system introduced by European merchants to other trading partners has prevailed (Bishop 1990). Similarly, during the 1800s, the understanding and Romanticizing of childhood as a sacred period of exploration and learning changed, and in combination with the attempt to regulate child labor, education became an instrument to socialize citizens (Benavot et al. 1991).

With the introduction of compulsory schooling and scientific advancements, there was a 'demystification of the world', as Weber (1972) called it; society developed toward rationalized explanations of reality and away from religious ones. At the same time, academic achievement and graduate certificates became a mark of status in and of themselves. They not only allow for occupational opportunities and social mobility but also mark the transition from adolescence to adulthood (Baker 2014). Graduating from school or dropping out have a significant influence on a person's self-perception as well as on the social evaluation by others. Education is considered a necessary requirement for citizens, whereas 'dropouts' are often regarded as nonproductive members of society (Baker 2014). The common usage of the word 'dropout' merges the act of leaving school early with personal failure; thus, it indicates a cultural transformation in terms of how people think about themselves and others (Papagiannis et al. 1983).

The standardization of education not only results in homogeneity of student knowledge but also in homogeneity of self-perception, namely, the experience of oneself as a citizen in a cultural (national) context. Childhood becomes a distinct and important part of the human lifecycle. Since every child has human rights by virtue of being a human individual, the experience of school education as a mythical yet rationalistic inauguration into full citizenship is shared across the globe (Ramirez 2013, 147). In a nutshell, educational standardization, national identity, culture, and globalization are inseparably interwoven.

The spread of state-led education all over the world has been obvious since the early nineteenth century; but what has been the impact of cultural similarities and differences in the facilitation of that expansion? Has culture been shaping the diffusion process within rather than between cultural spheres? 
In line with arguments highlighting the importance of identity and global identity politics (Fukuyama 2018), we expect cultural spheres to be relevant in shaping the development of compulsory education. We also expect them to have an effect on the diffusion of education policy. We regard global cultural differences as important but at the same time disagree with the assumption of there being rigid fault lines between cultures. Global cultures are fuzzy sets, meaning that the boundaries between cultural categories are merging, not clearly cut. We represent this fuzziness as a valued network, where countries are linked to each other by cultural proximity. The strength of ties increases with the number of shared cultural characteristics (Chap. 1), allowing for a gradual description of cultural similarity. Hence, we are ultimately interested in what effects this new operationalization of cultural similarity has on the timing of policies that mandate state-organized education.

\section{Data and Methods}

In this chapter, we analyze the worldwide diffusion of compulsory education from 1789 to 2010 . We collected data on cultural characteristics of $N=164$ countries, including indicators of political liberties, rule of law, aspects of gender roles and relations, dominant religion, language group, government ideology, classification of civilization, and colonial past (Besche-Truthe et al. 2020). We generated quartiles of continuous measurements, for example, for the index of gender relations, in order to get discrete categories for the valued two-mode network. If two countries share a characteristic, for example, the same dominant religion, they will be connected in the network. Regarding the multitude of cultural characteristics in our data set, most countries have several relations to each other, for example, when they share the language group 'Atlantic-Kongo' and the same category of political liberties. The weighted nature of this network derives from the number of shared characteristics; the higher the number of ties in this network, the closer the cultural proximity between two countries. Rather than homogenous clusters and clear-cut 'fault lines', this method yields a network of cultural spheres with relations of varying intensity between countries. We then applied the Louvain 
algorithm for clustering in order to cluster the countries. The algorithm finds communities by maximizing the density within communities relative to the links across communities. As shown in Figs. 2.2, 2.3, and 2.4, the cultural spheres network is time-varying due to the time-varying measurement of most cultural indicators. Elsewhere, we used the metaphor of a 'pipe structure' as the underlying structure of the diffusion process (Besche-Truthe et al. 2021), where the 'pipe diameter' is the number of ties in a dyad and thus, the degree of similarity between two countries. Larger pipe diameters lead to a higher weight of a tie and indicate higher 'cultural exposure' of Country A to Country B. This should increase the likelihood of 'contagion', given that a specific policy has not yet been adopted in one of the two countries. We use the $\mathrm{R}$ package netdiffuseR (Vega Yon and Valente 2020), which defines exposure as the share of $j$ adopters in the ego-centered network of node $i(i \neq j)$ at time $t$ and is supposed to affect the adoption rate between $t$ and $t+1$ (Valente 1995). If a country is only connected to other countries that have already adopted compulsory schooling, exposure is 1, and if none of these countries have adopted it, exposure is 0 . To be precise, we calculate the exposure weighted by the tie strength, which is lagged by one year, that is, the exposure one year before we observe a possible introduction.

The introduction of compulsory schooling ( no compulsory schooling $=0$ and introduction of compulsory schooling $=1$ ) during the window of observation is the dependent variable in our discrete-time logistic hazard model. Once a country has introduced compulsory schooling, it drops out of the risk set. Introductions after 2010 are right-censored, adoptions before the window of observation begins (before 1789) are not considered in the risk set but contribute to the network exposure of countries that have not yet adopted.

To account for specific unequal power relations, we introduce a second potentially influential network that is built through colonial ties of countries. In contrast to static colonial relations, we represent colonial ties in a time-variant way. The data set "COLDAT" by Bastian Becker (2019) was extended by including non-European colonizers like the Persian and the Russian Empires. Countries send a link with a value of 1 to countries who are their colonizers in the respective year. However, after colonization, the relationship between the two countries does not end; interlinkages still 
prevail, although through other channels like trade or development aid (Shields and Menashy 2017). Institutions initially founded during colonization might pose path dependencies. Generally, we expect a higher possibility for contact and orientation on policies between the former metropole and colonized state. We model these possibilities by a decreasing value of a colonial tie after colonization formally ended by accounting for 'post-colonial' ties using an exponential decay function.

Our 'cultural spheres' network and the network of (post-)colonial ties are the underlying structures for calculating a country's exposure to other countries that have already implemented compulsory schooling. We hypothesize exposure in the valued 'cultural spheres' network to be a relevant driving force behind the introduction of compulsory schooling, but we also account for relevant confounders. The introduction of compulsory schooling might also depend on a country's level of economic development, which is certainly not exclusively determined by culture but nevertheless correlates with countries' cultures (Weber 1972; Rose 2019). We interpolated Gross Domestic Product (GDP) per capita for the entire time frame by taking the minimum value in every income group based on all observations before 1800, where we filled missing values with this minimum value. To fill the historic time points, we took the last observed group per country and extrapolated the value for all previous years.

Although Paglayan $(2020,9)$ finds the event of democratization to occur approximately 50 years later than the introduction of compulsory primary schooling and generally argues that the expansion of primary school enrolments is not significantly larger in democratic time periods of nation-states, we still include an index representing the level of democratization ranging 0-9. We utilize data from the V-Dem Project (Coppedge et al. 2019) and linearly interpolated missing time points. We suspect that contrary to Paglayan's operationalization, using an index instead of a dummy variable captures country-level heterogeneity better. It is possible that nominally weak or undemocratic systems could be quicker in institutionalizing state-mandated education to ideologically secure their regime or pacify conflicts arising from economic and social inequalities. Finally, the process might be time-dependent, which is usually a result of unobserved heterogeneity. We control for five equally sized time intervals, beginning in the historical year of 1789 . 


\section{Results}

\section{Geographies of Compulsory Education Diffusion}

Geographically, the global diffusion process started in a few countries in Northern and Central Europe and then spread to the Americas and Australia. Until 1900, Japan as well as the Philippines had also adopted compulsory schooling. Until 1950, it is apparent that countries in subSaharan Africa had not introduced compulsory schooling, while China and Russia had adopted the policy by this point. By 2010, only 20 out of the observed 164 states had not introduced compulsory schooling. Figure 2.1 maps Rogers' $(2003,281)$ classification of early adopters, the early majority, the late majority, and laggards. These categories are derived from the distribution of times-of-adoption: times within one standard deviation around the mean time indicate the early and late majority; times below and above one standard deviation are early adopters and laggards. The initial hegemony of Western state formation (Green 2013) can be visualized though the diffusion pattern of compulsory schooling, where it originated in Europe and then spread across the globe. The hegemony of the Western education states has run its course since then (Weymann 2014).

The diffusion pattern of compulsory schooling shown in Fig. 2.1 supports Meyer et al.'s (1997) argument regarding the spread of Western institutions across the globe. Early adopters are mostly Western and some

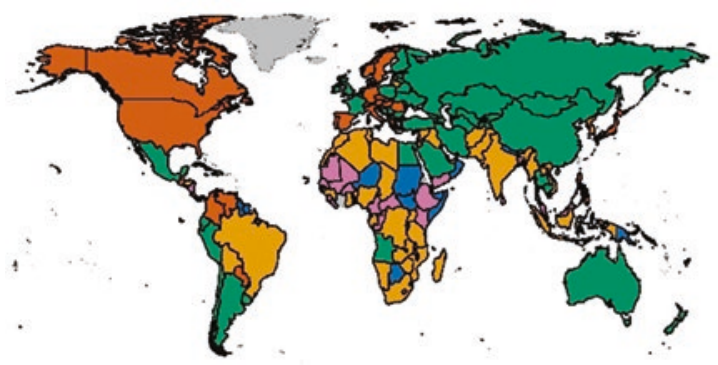

\section{Adopter Classification}

$\square$ Early Adopters - $n=27,<1874$

Early Majority $-n=49,1875-1926$ Late Majority $-n=47,1927-1980$

Laggards $-n=24,>1980$

Non-Adopters $-n=17$

Fig. 2.1 Diffusion of compulsory education around the world, 1789-2010. (Source: Own computation WeSIS database) 
South American countries, the early majority consists of most Asian and some Middle Eastern countries, whereas the late majority shows a high prevalence in Africa, South America, and South Asia. Alphabetization through standardized education fosters a culturally homogenized civil society and at the same time ensures the survival of state power by increasing the identification with the state. This process is bolstered by emphasizing the importance of education for the individuals' participation in the labor market, as stated above. The geography of adoption in Fig. 2.1 gives a first impression of how adopter-types are distributed across the globe. However, geographic location itself is not a meaningful explanation for the process. According to our argument, ties in the network of 'cultural spheres' that are derived from a two-mode network of countries and cultural characteristics are the backbone of the diffusion process. Hence, we now turn to a more thorough inspection of our 'cultural spheres'.

\section{Describing Cultural Spheres}

Figures 2.2, 2.3, and 2.4 show the one-mode projection of the two-mode network on the vertex set of countries after applying a Louvain clustering method for group detection (Luke 2015, 115-119). The vertices (nodes) are connected via shared cultural characteristics and labeled with the ISO-3-character code of the respective country they represent. The tie strength increases with more shared characteristics. Countries sharing multiple characteristics are therefore considered more similar than countries sharing only few or no characteristics. For a better overview, only ties with strength greater than 2 are depicted in these plots. A general rule for where countries are placed in the graph is as follows: highly similar countries are located closely together, outliers with only few ties such as China or Thailand (Fig. 2.2) are placed at the outer rim of the plot. The cluster solution obtained with the Louvain clustering algorithm sorts the countries into an optimal number of clusters based on the weight of the ties in any given year. For the year 1880 , this results in a solution with five clusters, as indicated by the colors (Fig. 2.2). The visualization makes the fuzzy boundaries obvious, as these clusters partially overlap and show 


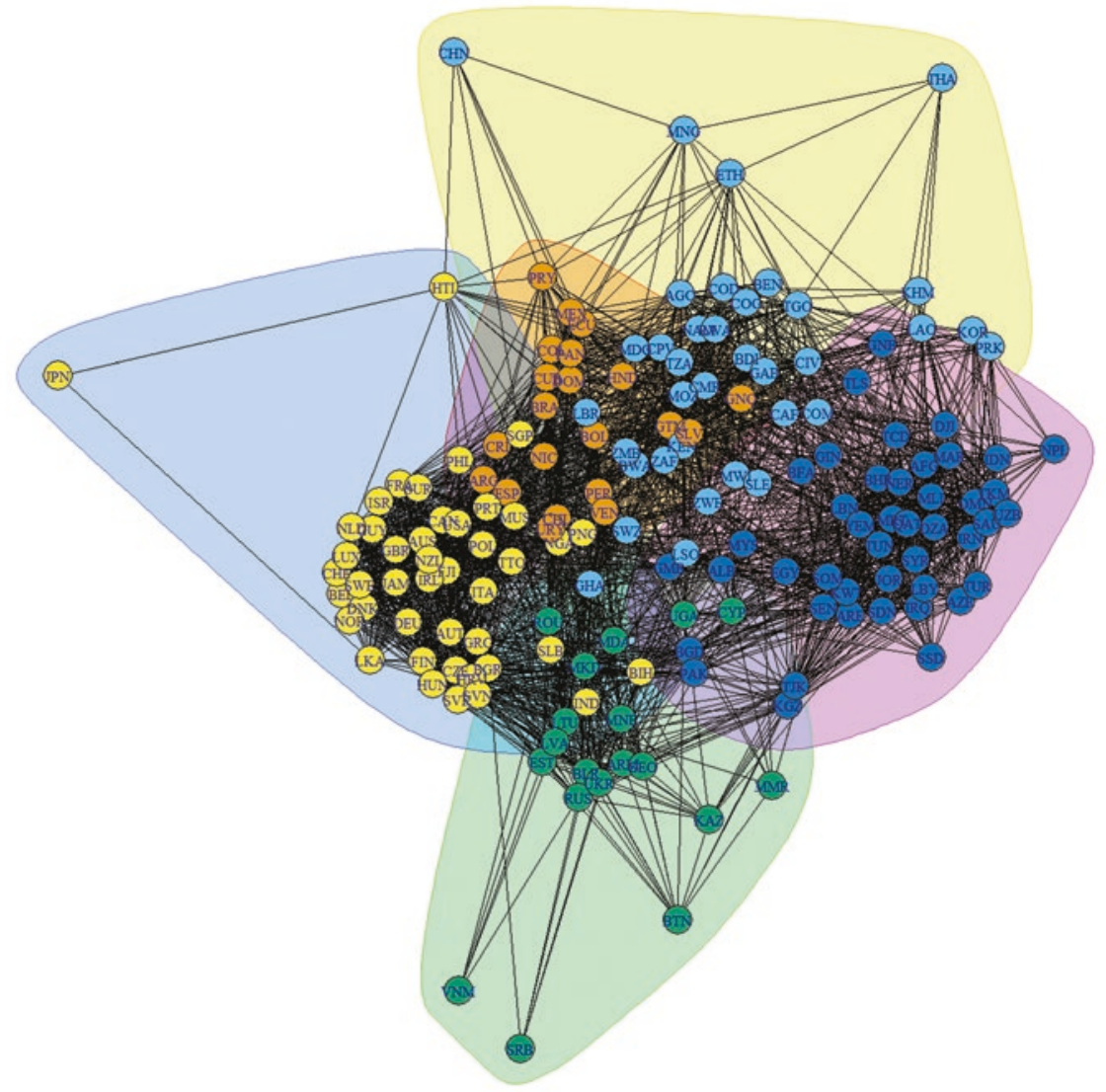

Fig. 2.2 Network of cultural spheres in 1880

many linkages across clusters. In 2010 (Fig. 2.4), the cluster solution collapses into only three categories, which underlines the time-varying nature of our cultural indicators, and there is certainly no static 'essence' of a culture. For our analysis, we use the five-cluster solution from 1880, which represents cultural spheres at the beginning of our window of observation. Inspecting countries in the respective clusters gives a meaningful result: cluster 1 consists of Catholic, Spanish-speaking countries; cluster 2 of not predominantly Muslim African and East Asian countries; cluster 3 of Eastern European and Asian countries; cluster 4 of mostly 


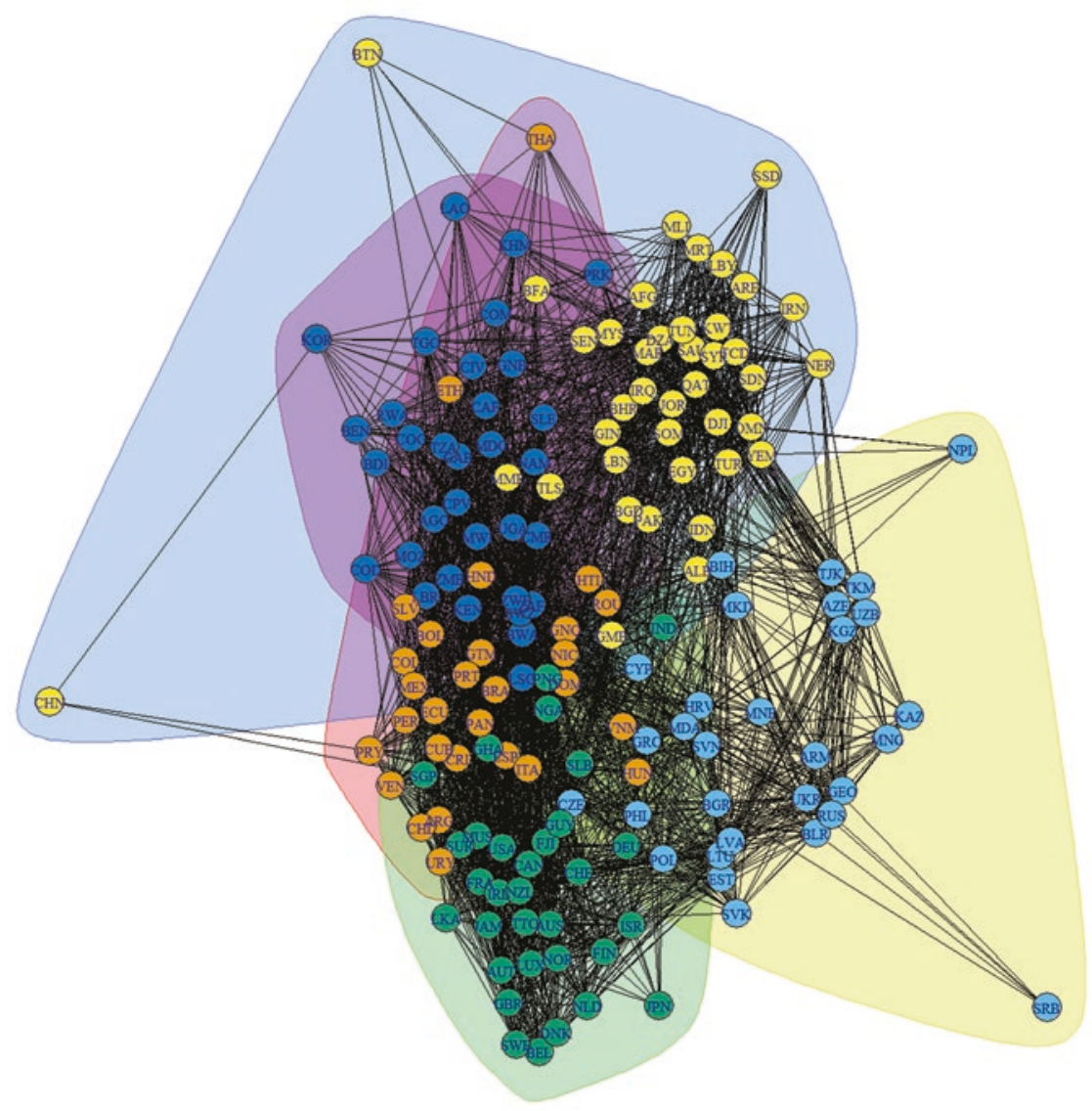

Fig. 2.3 Network of cultural spheres in 1945

WEIRD countries; and cluster 5 of predominantly Muslim countries. Also, the fuzzy set nature of our clustering approach reveals that some countries do not seem to fit perfectly into a group. For instance, the cluster Eastern European and Asian also includes Vietnam and Uganda as two outliers who have a rather marginalized position within this cluster (Fig. 2.2). In addition, Japan and Haiti belong to the WEIRD cluster, but they take a marginal position because the number and intensity of their ties to other members of this cluster are comparatively low. 


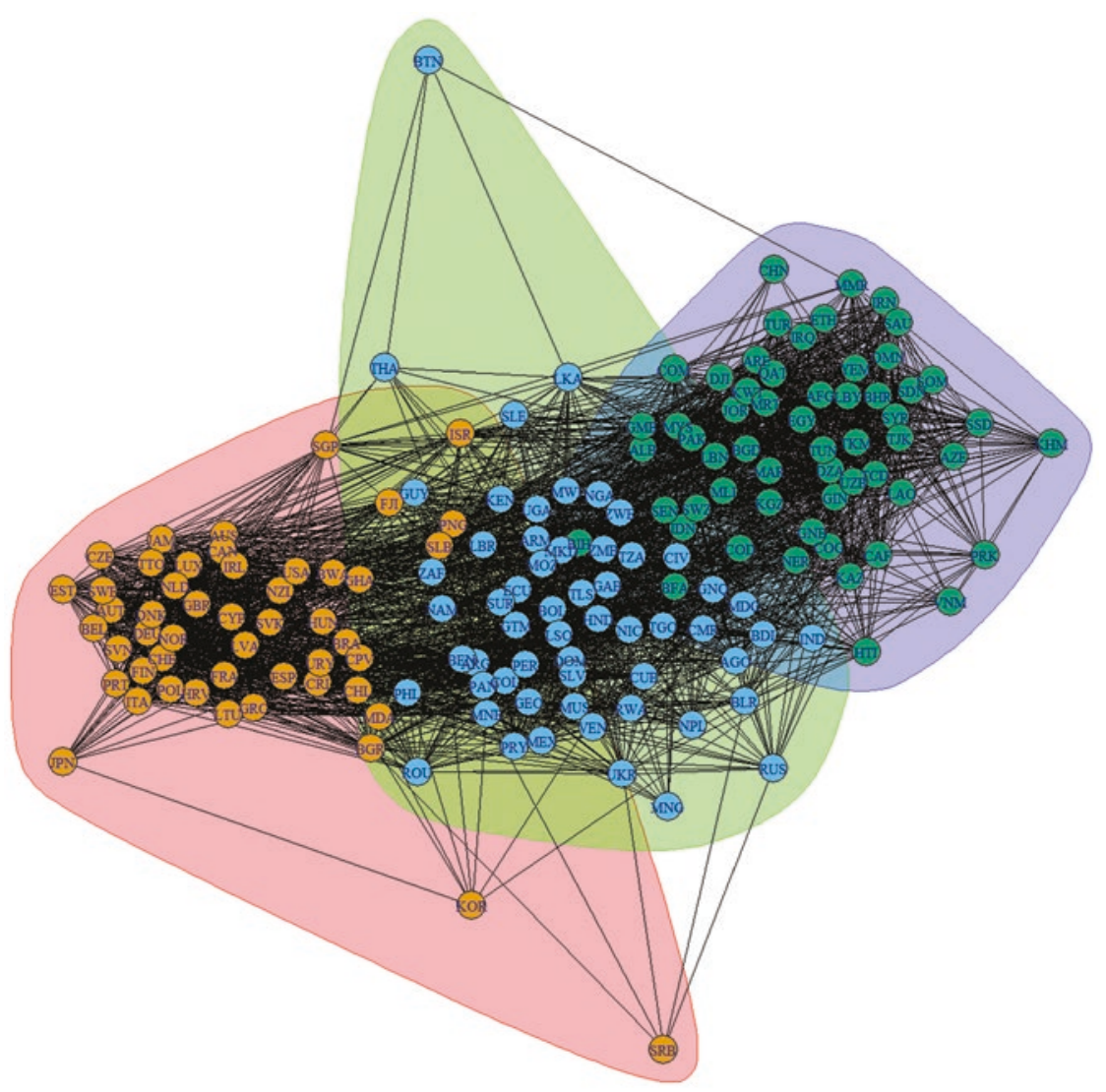

Fig. 2.4 Network of cultural spheres in 2010

Inspecting the cluster solution in 2010, we quickly notice several distinctions from the network in 1880 . First, there are only three clusters remaining, and still with considerable overlap. The aspects dividing countries in terms of cultural characteristics seem to move toward an equilibrium: While a constant stock of traits is shared, a constant stock of traits also remains exclusive. Second, the graph seems to have merged into a single hairball, causing a reduction in the number of outliers. While in 1880 countries such as Japan, Vietnam, Serbia, Bhutan, China, and Thailand shared only few characteristics with other countries, by 2010 only Japan, South Korea, and Serbia remained in this position. The 
orange cluster contains mostly WEIRD/Western countries, the green cluster mostly not predominantly Muslim countries, and the purple cluster mainly Muslim/African countries but also countries more difficult to place such as China. Despite the change in cluster membership and number, the overlap between the clusters is still obvious. The number of shared characteristics does not culminate in a separation of cultural clusters, nor is it intended to do so. Overall, the cluster solution provides a good classification and interesting insights.

We can deduce that our cluster solution is in line with other recent attempts to create a classification of cultural groups. For example, recent studies using the European and World Value Survey classified countries according to religious cultures and highlighted the differences between the Western and the Muslim world with respect to sexual liberalization and gender equality (Norris and Inglehart 2011, 154). Moreover, a multilevel view on global culture assumes three overarching 'hyper-cultures' and eight 'macro-cultures' in the world. While the former depends on legal systems (Islamic, Anglo-Saxon, Roman), macro-cultures result from systems of belief in different religions (Basáńez 2016, 163). Cultural spheres resulting from our clustering procedure are in line with previous studies, as indicators of religion, language, gender roles, and political liberties were also included as the basic characteristics for defining culture.

\section{Estimating the Influence of Culture on the Diffusion Process}

In the previous sections, we laid out in detail that 'culture' - not as a specific domestic essence, but rather as a relation to other countries' culturesis subject to change over time and interwoven with national policy-making as well as education policy more specifically. How culture can be influential is shown through the network diffusion models in Table 2.1.

Table 2.1 shows three discrete-time logistic hazard models of network diffusion (Valente 1995). Due to the interval-specific baseline hazards, it is a piecewise constant rate model. Countries that had adopted compulsory education before the process time began were included in the calculation of exposure but excluded from the logistic hazard model, as they are no longer at risk of adopting the policy. Only $N=160$ countries 
Table 2.1 Diffusion of compulsory education in the cultural spheres network

\begin{tabular}{|c|c|c|c|}
\hline & \multicolumn{3}{|c|}{$\begin{array}{l}\text { Introduction of compulsory } \\
\text { schooling }\end{array}$} \\
\hline & (1) & (2) & (3) \\
\hline Rate $\mathrm{t}(0-44)$ & $0.0003^{* * *}$ & $0.0002^{* \star \star}$ & $0.0001^{* \star *}$ \\
\hline Rate $\mathrm{t}(45-89)$ & $0.002^{* * *}$ & $0.002^{* * *}$ & $0.002^{* * *}$ \\
\hline Rate $t(90-129)$ & $0.001^{* \star *}$ & $0.002^{\star * \star}$ & $0.004^{* \star *}$ \\
\hline Rate $t(130-169)$ & $0.001^{\star \star *}$ & $0.002^{\star \star *}$ & $0.008^{\star \star \star}$ \\
\hline Rate $t(170-221)$ & $0.001^{* * *}$ & $0.002^{* * *}$ & $0.024^{* * *}$ \\
\hline GDP per capita/10,000 USD & 1.042 & 1.023 & 1.037 \\
\hline Democratization & 1.039 & 1.015 & 1.064 \\
\hline Cultural spheres netw.: w. exposure (lag 1 year) & $158.652^{* * *}$ & $40.625^{* \star *}$ & - \\
\hline Colonies netw.: w. exposure & 1.387 & 1.28 & - \\
\hline Clu. 1: Catholic, Spanish-speaking & - & $2.012^{*}$ & $3.451^{* * *}$ \\
\hline $\begin{array}{l}\text { Clu. 2: Not predominantly Muslim African/ East } \\
\text { Asian }\end{array}$ & - & 0.752 & 0.895 \\
\hline Clu. 3: Eastern European and Asian & - & $2.224^{\star *}$ & $2.897^{\star \star \star}$ \\
\hline Clu. 4: WEIRD & - & $1.916^{*}$ & $3.031^{* * *}$ \\
\hline Clu. 5: Predominantly Muslim & - & Ref. & Ref. \\
\hline Observations & 21,910 & 21,910 & 21,910 \\
\hline Log likelihood & -748.251 & -738.824 & -746.366 \\
\hline Akaike Inf. Crit. & 1514.503 & 1503.649 & 1514.731 \\
\hline
\end{tabular}

Discrete-time event history model, hazard ratios, $N=160$ countries

Source: WeSIS database, own computation

Note: $+p<0.1 ;{ }^{*} p<0.05 ;{ }^{* *} p<0.01 ;{ }^{* * *} p<0.001$

remain in the risk set. The first model estimates the effects of (weighted) exposure in networks of cultural spheres lagged for one year, colonial history, and controlling for GDP per capita and levels of democratization. We adjusted the standard errors for time periods in which several countries belonged to an overarching entity. Serbia and Macedonia, for instance, were once part of the former Yugoslavia. Their adoption times are not necessarily independent from each other and require a correction of the standard errors (Zeileis et al. 2020).

We get a positive, strong, and significant effect of weighted exposure in the cultural spheres network on the adoption rate in Model (1), whereas the effect of weighted exposure in the network of colonial histories is insignificant. In line with our expectation, the network of cultural spheres is an underlying structure for the diffusion of compulsory education among countries. Including dummy variables of the cultural spheres-clusters in Model (2) does not substantially alter the direction and significance of 
exposure. The cultural spheres dummies show significant effects in Model (2). Moreover, three cultural spheres significantly accelerate the adoption process in Model (3), where we excluded the exposure effects from the estimation. The reference group is cluster 5, which is the cultural sphere of countries with a predominantly Muslim population. The reference group was chosen due to its large intra-cluster difference. Compared with this reference group, effects of the not predominantly Muslim African/East Asian cultural sphere do not significantly differ. These countries show no accelerated adoption speed compared to predominantly Muslim countries. In contrast, the adoption rate is increased by a factor of $2.897^{* * *}$ in the Eastern European and Asian cultural sphere compared with the reference group in Model (3) and is even increased by a factor of $3.031^{* * *}$ in the WEIRD cluster and by $3.451^{* * *}$ in the Catholic, Spanish-speaking cluster. We observe strong evidence for diffusion through 'pipes' built from cultural similarity, the sheer membership in a cultural sphere does significantly raise the adoption rate of a first compulsory education law in most cases. Regardless of the exposure through the cultural network, the membership in the clusters 1, 3, and 4 (Catholic, Spanish-speaking, Eastern European and Asian, and WEIRD) significantly influences the adoption of compulsory education positively. In Model (2), the adoption rate is increased by the factors $2.101^{*}, 2.276^{* *}$, and $1.954^{*}$ respectively, supporting our hypothesis that culture around the globe can have an accelerating effect on the diffusion of compulsory education.

These results clearly signify culture as a relevant variable in macroquantitative social science studies, where using a relational approach brings mechanisms to the fore that would normally be unobserved when using rigid and clear-cut categorizations. We demonstrate that the risk of adopting compulsory education for any given state is significantly heightened by the adoption of compulsory education in a culturally similar country. Moreover, not predominantly Muslim African/East Asian and predominantly Muslim countries show remarkable differences in the timing of compulsory schooling introduction. Once exposure through cultural similarity increases, the risk of policy adoption increases as well. Furthermore, this result corroborates what the map of adopter types (Fig. 2.1) suggested: Formalization of education through the introduction of educational institutions appears to be a WEIRD project. However, 
when institutionalized education crosses over to other cultural spheres, it spreads rapidly within that sphere. As predicted by neo-institutionalism, it seems difficult for countries in other cultural spheres to elude the adoption in the long run; according to our theoretical considerations, we expected that cultural spheres would mediate the adoption process.

\section{Conclusion}

Cultures differ remarkably around the globe. Even though the definition of culture and the identification of an appropriate level of abstraction are far from trivial, our empirical analysis reveals different cultural spheres in the world. Acknowledging these differences at an abstract level does not necessarily mean to "stereotype and exoticize other people" (AndersonLevitt 2012, 441). Contrariwise, from a European academic's perspective, our 'own' culture and psychology appear exotic and WEIRD (Henrich 2020). Today's predominantly WEIRD culture relies on properly operating and legitimate state institutions, which in contrast to premodern clan societies are the modern form of social order. Public education systems organize the reproduction of culture and often provide efficient governability of the literate population by legitimating state activity. Often, they increase the WEIRD-ness of a population, and it is not surprising that the propensity to establish such educational programs differed historically between nation-states. A 'rational' organization of the state, the economy, and other 'spheres of life' (Weber 1972), each endowed with its own criteria of rationality (Lepsius 1994), is a crucial component of modernity. The rationalization of these 'spheres of life', including education, resulted in powerful technology and social organization as never seen before. But Weber noticed the destructive potential of this development and influenced later critical theory (Lukács 1968) when he described the efficiency of bureaucratic authority as an iron cage'. Neo-institutionalism further elaborated these theoretical considerations and motivated our hypothesis of a global diffusion of education policy - in our case, the introduction of compulsory education mediated by 'cultural spheres'. We developed the concept of 'cultural spheres' as a response to classifications of cultures that ignore their fuzzy-set nature 
and their overlapping boundaries. Even today, differences between cultural spheres become apparent in our data. These include differences relating to indicators of gender roles, dominant religion, language group, and political liberties. The results of clustering our time-varying twomode networks consisting of countries and cultural characteristics as node sets revealed five cultural clusters with overlapping boundaries; but these clusters nevertheless result in a meaningful typology of Catholic, Spanish-speaking, not predominantly Muslim African and East Asian, Eastern European and Asian, WEIRD, and predominantly Muslim countries. Modern states cannot exist without literacy and basic education (Weymann 2014), so it is not surprising that state-mandated education began in Western countries and ultimately spread globally.

While ties in the network of cultural spheres strongly influence the diffusion process of compulsory education, we did not find evidence for diffusion via the network of colonial histories. Furthermore, while the WEIRD cultural sphere does not show the highest adoption rate, the Catholic, Spanish-speaking cluster does. Compared with the other four cultural spheres, the adoption rate is significantly higher in the Catholic, Spanish-speaking cluster (Model (3) in Table 2.1). In line with our expectations, cultural spheres considerably mediate the diffusion of compulsory education. Moreover, we show that viewing culture in a relational way, that is, showing the fuzzy boundaries of states grouped together, instead of in a rigid way, that is, in terms of 'fault lines', is beneficial in uncovering diffusion patterns. Although we just analyzed the introduction of compulsory education as a formal institution without considering any content or curriculum, our results highlight that culture and cultural change strongly affect the identity of groups and individuals. As a consequence, "when global ideas enter a local arena, meanings are re-made not only because local actors inevitably reinterpret ideas in the context of their own frameworks, but also because they may struggle against the meanings offered or imposed by global actors" (Anderson-Levitt 2012, 451).

An important limitation of our macro-quantitative diffusion analysis is the abstract perspective on times-of-adoption, without specifying the micro-mechanisms of how countries prepare the decision to adopt the policy. Referring to previous studies, theoretically elaborating diffusion mechanisms (Gilardi 2016) and providing empirical evidence does not 
solve this problem because our data does not provide any information on which particular mechanism was at work when, for example, Chile or Pakistan introduced compulsory education. Therefore, future research should combine diffusion analysis with qualitative case studies. Another limitation of this chapter is the focus on horizontal interdependencies, that is, networks between countries. Due to the strong influence of international organizations in education policy-making in recent years, it might be interesting to include a membership network of different IOs in future publications.

\section{References}

Acemoglu, Daron, and James A. Robinson. 2019. The Narrow Corridor: States, Societies, and the Fate of Liberty. New York: Penguin Press.

Anderson-Levitt, Kathryn M. 2012. Complicating the Concept of Culture. Comparative Education 48 (2): 441-454. https://doi.org/10.1080/0305006 8.2011.634285.

Baker, David. 2014. The Schooled Society: The Educational Transformation of Global Culture. Stanford: Stanford University Press.

Basáñez, Miguel. 2016. A World of Three Cultures: Honor, Achievement and Joy. Oxford: Oxford University Press.

Becker, Bastian. 2019. Colonial Dates Dataset (COLDAT). Harvard Dataverse. https://doi.org/10.7910/DVN/T9SDEW.

Benavot, Aaron, and Phyllis Riddle. 1988. The Expansion of Primary Education, 1870-1940: Trends and Issues. Sociology of Education 61 (3): 191-210. https://doi.org/10.2307/2112627.

Benavot, Aaron, Yun-Kyung Cha, David Kamens, John W. Meyer, and SukYing Wong. 1991. School Knowledge for the Masses: World Models and National Primary Curricular Categories in the Twentieth Century. American Sociological Review 56 (1): 85-100. https://doi.org/10.2307/2074396.

Besche-Truthe, Fabian, Helen Seitzer, and Michael Windzio. 2020. Cultural Spheres_Creating a Dyadic Dataset of Cultural Proximity. SFB 1342 Technical Paper Series/5/2020, Bremen: SFB 1342.

- 2021, forthcoming. Global 'Cultural Spheres' and the Introduction of Compulsory Schooling around the World. In Impacts on Social Policy. Short 
Histories in a Global Perspective, ed. Frank Nullmeier, Delia González de Reufels, and Herbert Obinger. Cham: Palgrave Macmillan.

Bishop, Alan J. 1990. Western Mathematics: The Secret Weapon of Cultural Imperialism. Race \& Class 32 (2): 51-65. https://doi. org/10.1177/030639689003200204.

Böckenförde, Ernst-Wolfgang. 1976. Staat, Gesellschaft, Freiheit: Studien zur Staatstheorie und zum Verfassungsrecht. Frankfurt am Main: Suhrkamp.

Boli, John, Francisco O. Ramirez, and John W. Meyer. 1985. Explaining the Origins and Expansion of Mass Education. Comparative Education Review 29 (2): 145-170. https://doi.org/10.1086/446504.

Coppedge, Michael, John Gerring, Carl Henrik Knutsen, Staffan I. Lindberg, Jan Teorell, David Altman, Michael Bernhard, et al. 2019. V-Dem Dataset V9. Varieties of Democracy (V-Dem) Project.

Craig, John E. 1981. Chapter 4: The Expansion of Education. Review of Research in Education 9 (1): 151-213. https://doi.org/10.3102/0091732X009001151. Emirbayer, Mustafa. 1997. Manifesto for a Relational Sociology. American Journal of Sociology 103: 281-317. https://doi.org/10.1086/231209 .

Emirbayer, Mustafa, and Jeff Goodwin. 1994. Network Analysis, Culture, and the Problem of Agency. American Journal of Sociology 99: 1411-1454. https:// www.jstor.org/stable/2782580.

Finnemore, Martha. 1993. International Organizations as Teachers of Norms: The United Nations Educational, Scientific, and Cultural Organization and Science Policy. International Organization 47 (4): 565-597. doi:10.1017/ S0020818300028101.

Fukuyama, Francis. 2018. Identity: The Demand for Dignity and the Politics of Resentment. New York: Farrar, Straus and Giroux.

Gilardi, Fabrizio. 2016. Four Ways We Can Improve Policy Diffusion Research. State Politics \& Policy Quarterly 16: 8-21. https://doi. org/10.1177/1532440015608761.

Green, Andy. 2013. Education and State Formation: Europe, East Asia and the USA. 2nd ed. Education, Economy and Society. Basingstoke: Palgrave Macmillan.

Henrich, Joseph. 2016. The Secret of our Success: How Culture is Driving Human Evolution, Domesticating our Species, and Making Us Smarter. Princeton: Princeton University Press.

- 2020. The Weirdest People in the World: How the West Became Psychologically Peculiar and Particularly Prosperous. Bristol: Allen Lane.

Huntington, Samuel P. 1993. The Clash of Civilizations? Foreign Affairs 72: 22-49. https://doi.org/10.2307/20045621. 
1996. The Clash of Civilizations and the Remaking of World Order.

New York: Simon and Schuste.

Lepsius, Rainer. 1994. The European Community: Regime-building and Institutionalization of Criteria of Rationality. In Social Change and Political Transformation, ed. Chris Rootes and Howard Davis, 27-38. London: University College London Press.

Lockwood, David. 1992. Solidarity and Schism: 'The Problem of Disorder' in Durkheimian and Marxist Sociology. Oxford: Clarendon Press.

Lukács, Georg. 1968. Geschichte und Klassenbewusstsein. Neuwied: Luchterhand. Luke, Douglas. 2015. A User's Guide to Network Analysis in R. New York: Springer. Meyer, John, and Brian Rowan. 1977. Institutional Organizations: Formal Structure as Myth and Ceremony. American Journal of Sociology 83: 340-363. https://doi.org/10.1086/226550.

Meyer, John W., John Boli, Georg Thomas, and Francisco Ramirez. 1997. World Society and the Nation-State. American Journal of Sociology 103: 144-181. https://doi.org/10.1086/231174.

Morin, Olivier. 2016. How Traditions Live and Die. New York: Oxford University Press.

Norris, Pippa, and Ronald Inglehart. 2011. Sacred and Secular: Religion and Politics Worldwide. 2nd ed. Cambridge: Cambridge University Press.

Paglayan, Augustina. 2020. The Non-Democratic Roots of Mass Education: Evidence from 200 Years. American Political Science Review, 1-20. https:// doi.org/10.1017/S0003055420000647.

Papagiannis, George, Robert Bickel, and Richard Fuller. 1983. The Social Creation of School Dropouts: Accomplishing the Reproduction of an Underclass. Youth \& Society 14 (3): 363-392. https://doi.org/10.117 7/0044118X83014003006.

Parsons, Talcott, and Edward Shils. 1951. Values, Motives, and Systems of Action. In Toward a General Theory of Action, ed. Talcott Parsons and Edward Shils, 45-275. Cambridge: Harvard University Press.

Ramirez, Francisco O. 2013. Reconstituting Children: Extension of Personhood and Citizenship. In Age Structuring in Comparative Perspective, ed. David I. Kertzer and K.W. Schaie, 143-166. Hoboken: Taylor and Francis.

Ramirez, Francisco O., and John Boli. 1987. The Political Construction of Mass Schooling: European Origins and Worldwide Institutionalization. Sociology of Education 60 (1): 2-17. https://doi.org/10.2307/2112615.

Rogers, Everett M. 2003. Diffusion of Innovations. 5th ed. New York: Free Press. Rose, David. 2019. Why Culture Matters Most. New York: Oxford University Press. 
Schriewer, Jürgen, ed. 2012. Discourse Formation in Comparative Education. Comparative Studies Series. 4th ed. Bern: Peter Lang.

Schulz, Jonathan, Duman Bahrami-Rad, Jonathan Beauchamp, and Joseph Henrich. 2019. The Church, Intensive Kinship, and Global Psychological Variation. Science 366 (707): 1-12. https://doi.org/10.1126/science.aau5141. Shields, Robin, and Francine Menashy. 2017. The Network of Bilateral Aid to Education 2005-2015. International Journal of Educational Development 64: 74-80. https://doi.org/10.1016/j.ijedudev.2017.07.003.

Steiner-Khamsi, Gita. 2000. Transferring Education, Displacing Reforms. In Discourse Formation in Comparative Education, ed. Jürgen Schriewer, 4th ed., 155-187. Peter Lang.

Strang, David, and John W. Meyer. 1993. Institutional Conditions for Diffusion. Theory and Society 22 (4): 487-511. https://doi.org/10.1007/BF00993595. Valente, Thomas W. 1995. Network Models of the Diffusion of Innovations. New Jersey: Hampton.

Vega Yon, George, and Thomas W. Valente. 2020. NetdiffuseR: Analysis of Diffusion and Contagion Processes on Networks. https://doi.org/10.5281/ zenodo.1039317.

Wallerstein, Immanuel. 2007. World-Systems Analysis: An Introduction. 5th ed. Durham, NC: Duke University Press.

Weber, Max. 1972. Wirtschaft und Gesellschaft: Grundriß der verstehenden Soziologie. Tübingen: Mohr.

Weymann, Ansgar. 2014. States, Markets and Education. The Rise and Limits of the Education State. Cham: Palgrave Macmillan.

Zeileis, Achim, Susanne Köll, and Nathaniel Graham. 2020. Various Versatile Variances: An Object-Oriented Implementation of Clustered Covariances in R. Journal of Statistical Software 95: 1-36. https://doi.org/10.18637/ jss.v095.i01. 
Open Access This chapter is licensed under the terms of the Creative Commons Attribution 4.0 International License (http://creativecommons.org/licenses/ by/4.0/), which permits use, sharing, adaptation, distribution and reproduction in any medium or format, as long as you give appropriate credit to the original author(s) and the source, provide a link to the Creative Commons licence and indicate if changes were made.

The images or other third party material in this chapter are included in the chapter's Creative Commons licence, unless indicated otherwise in a credit line to the material. If material is not included in the chapter's Creative Commons licence and your intended use is not permitted by statutory regulation or exceeds the permitted use, you will need to obtain permission directly from the copyright holder.

(c) (i) 